\title{
Clinical features and risk factors of angiography headache and evaluation of its relationship to primary headaches - an important but neglected problem
}

\author{
Izabela Domitrz \\ Department of Neurology, Medical Faculty, Medical University of Warsaw, Warsaw, Poland
}

\begin{abstract}
Introduction. The authors of the article published in the current edition a single-centre prospective cohort study featuring patients who had undergone a diagnostic cerebral angiography procedure and who had experienced a headache associated with the procedure [1]. The authors of 'Clinical features and risk factors of angiography headache and evaluation of its relationship to primary headaches' have addressed a common, but rarely discussed, problem of a headache associated with a cerebral angiography procedure - the angiography headache (AH).

Clinical reflections. AH was found in almost a quarter of the patients who had undergone angiography, and was found to be associated with female gender, higher education level, and a history of primary headache.

Clinical implications. It is worth remembering that migraine and tension type headaches are common predisposing factors to headache during and after this procedure.
\end{abstract}

Key words: angiography headache, migraine, tension type headache

(Neurol Neurochir Pol 2019; 53 (6): 400-401)

Angiography headache $(\mathrm{AH})$ is recognised in the International Classification of Headache Disorders - 3rd edition (ICHD-3) from 2018 [2] as a headache caused directly by a cerebral angiography. This diagnosis appears at 6.7.2 in the section on secondary headaches under the heading 'Headache attributed to other acute intracranial disorder'. According to the International Headache Society (HIS), AH is recognised when the headache meets these diagnostic criteria:

A. Any new headache fulfilling criterion C.

B. Intra-arterial carotid or vertebral angiography has been performed.

C. Evidence of causation demonstrated by at least two of the following:

1. headache has developed during or within 24 hours of the angiography,

2. headache has resolved within 72 hours after the angiography,
3. headache has one of the following sets of characteristics:

a) developed during contrast injection and lasted < 1 hour,

b) developed a few hours after the angiography and lasted $>24$ hours,

c) occurred in a patient with migraine without aura or with aura.

D. Cannot be better accounted for by another ICHD-3 diagnosis [2].

It is worth noting that some forms of AH occur during angiography and are closely related to the contrast injection, or occur later but within 24 hours, and that a migraine attack can be triggered by angiography [3]. These forms of $\mathrm{AH}$ are more common in patients with a history of primary headache, but are distinctly different in character from a primary headache. In all cases with $\mathrm{AH}$, reversible cerebral vasoconstriction syndrome (RCVS) as a haemorrhagic or

Address for correspondence: Izabela Domitrz, Department of Neurology, Medical Faculty, Medical University of Warsaw, Warsaw, Poland,

e-mail: izabela.domitrz@wum.edu.pl 
ischaemic stroke predictive symptom should be suspected, and excluded by performing magnetic resonance imaging. Angiography in RCVS is typically abnormal, with alternating segments of arterial constriction and dilatation, but it also can be normal during the first week after clinical onset [2].

There are only a few AH studies reported in the literature, with the first one being that of Ramadan et al. from 1995. The authors interviewed 45 patients who underwent a transfemoral cerebral angiography, and a post-angiography headache developed in $33 \%$ of patients [4]. A more recent study [5] included 327 patients of whom $55.6 \%$ developed $\mathrm{AH}$, mainly with a previous history of headaches. In the light of known reports, the current work [1] is of considerable value - the study group consisted of 226 patients and the frequency of $\mathrm{AH}$ was found to be $22 \%$. The authors define the AH risk group as female, higher educated patients with a previous history of primary headache. The problem of headache after cerebral angiography seems to be frequent, but has received little attention.

\section{References}

1. Demir T, Onan HB, Balal M, et al. Clinical features and risk factors of angiography headache and evaluation of its relationship to primary headaches. Neurologia i Neurochirurgia Polska. 2019; 53(6): 442-448, doi: 10.5603/pjnns.a2019.0058.

2. Headache Classification Committee of the International Headache Society (IHS) The International Classification of Headache Disorders, 3rd edition. Cephalalgia. 2018; 38(1): 1-211, doi: 10.1177/0333102417738202.

3. Aktan Ç, Özgür Ö, Sindel T, et al. Characteristics of headache during and after digital substraction angiography: A critical re-appraisal of the ICHD-3 criteria. Cephalalgia. 2017; 37(11): 1074-1081, doi: 10.1177/0333102416665878, indexed in Pubmed: 27558501.

4. Ramadan NM, Gilkey SJ, Mitchell M, et al. Postangiography headache. Headache. 1995; 35(1): 21-24, doi: 10.1111/j.1526-4610.1995. hed3501021.x, indexed in Pubmed: 7868330.

5. Kwon MA, Hong CK, Joo JY, et al. Headache After Cerebral Angiography: Frequency, Predisposing Factors, and Predictors of Recovery. J Neuroimaging. 2016; 26(1): 89-94, doi: 10.1111/jon.12290, indexed in Pubmed: 26331267. 